ision. These results opened up the field of bacterial genetics. Just like Delbrück and Ellis's earlier results on phage, they involved nothing that could not have been found out years earlier; the only new ingredient was clear thought.

In the ecology of science the opening of a new habitat immediately attracts a crowd. Delbrück escaped from it by switching to phototropism of the fungus Phycomyces, hoping again that simple experiments and clear thinking would lead him to a breakthrough. Twenty years of work, however, failed to bring the solution of this very difficult problem any nearer.

Fischer's biography reveals Delbrück as a German Romantic searching for the

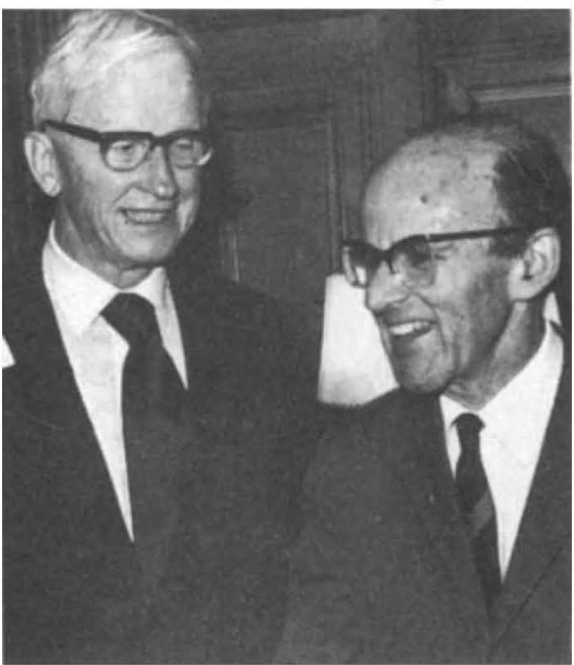

Double Max - Max Perutz (right) with Delbrück at a birthday party for Linus Pauling.

Holy Grail, which for him was Bohr's "Elementary Fact of Life". To those like myself, who have tried to understand the workings of large biological molecules in terms of simple chemical laws, Bohr's and Delbrück's belief in some mystical principle looks like vitalism, but this book has led me to understand the motive behind Delbrück's proverbial and often misplaced scepticism of new work. For example, he objected to Beadle and Tatum's one-gene-one-enzyme hypothesis on the ground that it could not be falsified by experiment; he dismissed Lwoff's lysogeny of phage as a non-phenomenon; and he disbelieved Meselson and Stahl's demonstration of the semi-conservative replication of DNA. Fischer writes that Delbrück wanted to model himself on his two great teachers by combining Bohr's insights with Pauli's mordant criticism, or, as he put it, by becoming God and Mephisto all in one. But I have the impression that Delbrück really wanted to disbelieve any advance that removed the elusive "Elementary Fact" further from his grasp.

Max Perutz is at the Medical Research Council's Laboratory of Molecular Biology, Hills Road, Cambridge CB2 $2 Q H$, UK.

\section{Explanation for the amiable physicist}

\section{Horace Freeland Judson}

The Problems of Biology. By John Maynard Smith. Oxford University Press: 1986. Pp. 134. Hbk £12.95, \$19.95; pbk $£ 4.95, \$ 6.95$.

WHAT are "the problems of biology"? The notion is ambiguous. We could mean the next unanswered but perhaps accessible large questions - in effect, the list we would offer of the most promising lines of research on which a graduate student in biology might found a prize career. Or we could mean the approaches and constraints that distinguish biology from other sciences - in other words, the considerations we would explain to an amiable theoretical physicist who asks (as some still do) why biology doesn't provide real answers, why the ratio of theory to data seems so inordinately low. The latter sense of the problems provoked Ernst Mayr to the declaration of biology's epistemological independence with which, four years ago, he opened The Growth of Biological Thought - three chapters that together ran to nearly twice the length of the entire book in which John Maynard Smith now marshals the problems of the former sort, the questions biologists are getting on with.

Yet the semantic fork has a handle. The fundamental problem of biology in either sense is the presence, in systems of immense complexity, of the element of the contingent - of the accidents of history. That is, in everything that is to be explained, whether we are considering, say, the nature of mutations in regulatory genes, or the behaviour of a given mammal, or the array and interrelationships of all species surviving at a given moment, we confront phenomena shaped by uncountably long sequences of past events, many of them random. Contingency characterizes life from its origin. Darwin put history into biology and we're still working out the consequences.

Contingency, for many biologists, is normally an aspect of the background; but for the biology Maynard Smith practises it's up front. He is, after all, a population geneticist (and the recent target of a Festschrift) who has written a longrunning paperback on evolutionary theory and who has in this past decade been modelling theorems of sociobiology as simple games. He says he agreed to write this new book for two reasons. $\mathrm{He}$ was flattered by the opportunity to

- Also published in this series (OPUS) are The Problems of Evolution (by Mark Ridley) and The Problems of Chemistry (by W. Graham Richards). measure himself against Bertrand Russell's The Problems of Philosophy. More important, he had been brought up on "the popular books of Eddington, Jeans, Einstein, Haldane and Wells" to believe that "the fundamental ideas of science can be explained to anyone willing to make the effort needed to understand them". The Problems of Biology has most of the virtues of that splendid tradition. It is sensible, colloquial, bracingly lucid, and stripped, sometimes daringly, to essentials. The comparison that sprang to my mind is Lawrence $\mathbf{J}$. Henderson's The Fitness of the Environment - a classic (incidentally American) that pre-dates that (chiefly British) line Maynard Smith recalls. One rises from each of these lean volumes with a sense of the world not merely clarified but put in order; one leaves the table with an appetite.

The definition of life is not now a real problem, as it was even four decades ago when Erwin Schrödinger's What Is Life? was attracting physicists into biology; but Maynard Smith takes it as an obligatory starting point. He re-states the two characteristics that we have come to recognize as definitive. First, living organisms, always in populations, reproduce, and not simply by multiplication - as does a fire - but by means of a hereditary mechanism such that like begets almostlike and the population evolves individuals successively more adapted for survival. Secondly, an organism is "a complex structure which is maintained by the energy flowing through it". Maynard Smith calls these two aspects of what we want to understand about any living creature or process the "ultimate and the proximal causes", adopting terminology that Mayr, for one, used. Ultimate causes are evolutionary, proximal causes functional in the sense that they answer the question "how?" in terms of immediate process. Heredity, which in the narrow sense of genetics has become "perhaps the best understood and least problematic area of biology", Maynard Smith considers to be the necessary prelude to the cluster of ultimate problems: the evolutionary process, the origins of sexual recombination, the levels of life and the patterns of nature (the species and their interactions) that have resulted from evolution. He starts the proximal problems with the organism's methods of achieving stability and controlled responses at the biochemical level, and goes on to animal behaviour, neurobiology, and the development and differentiation of the organism. He gives his tenth and final chapter to the origin of life. The list is canonical, the particular questions within these categories incisively posed, the examples apt

Yet a book both brief and universal also requires an organizing principle. The right one was to hand in the all-pervasive 
contingency of biological phenomena. Maynard Smith fails to exploit it. The argument runs along the following lines. The unsolved proximal topics, to begin with, are intimately related. As he notes, two are chief among them: development and behaviour. At least since William Harvey and the realization that omne vivum ex ovo, development and differentiation has been the great intractable problem. We now see that it subsumes, for higher organisms, the problem of the controls on biochemical activity in the individual cell - for these, directly or at one remove, are special cases of gene expression. We see that the most extreme elaboration of development is presented by the differentiation of the immune system (a problem of the first rank, surely, but not addressed by Maynard Smith) and of the nervous system and brain. We now get the first glimpses of a relationship, at the level of receptors common to lymphocytes and nerve cells, between the immune and nervous systems, whose mutual interactions are giving rise to an unexpected new field, behavioural immunology. We are reminded that receptors on neurones are to be understood - Jean-Pierre Changeux has been pressing this point - as allosteric proteins, which, of course, were first recognized as control elements within the cell. The essence of allosteric proteins is that they permit networking of responses free of chemical stringencies. All this suggests that the problem of development even implicates the problem of behaviour, so far as that can be approached from the bottom up.

Development and its subsidiary problems are as difficult as they are for at least two reasons: the individuals and systems in which we are most interested are complex beyond imagining, perhaps beyond describing, and the vast blueprint for what we encounter as this proximal complexity is itself a palimpsest, layer upon layer upon ancient layer of alterations each of which could only arise directly from what was available immediately before. In evolutionary biology the most contentious problems are the nature of the changes that have led to speciation and the rates at which evolution has taken plase, along with the special case of the evolution of animal and human behaviour. The unifying relationship here returns to the control genes that determine development, in particular how these mutate, perhaps accounting for bursts of evolutionary change. To fathom the proximal we require the ultimate, and the other way around: biology is intrinsically, in part, ad hoc - as we were explaining to the amiable physicist.

Horace Freeland Judson is Professor in and Director of the Program in Science and Writing, Johns Hopkins University, Baltimore, Maryland 21218, USA

\section{Taking the tablets}

\section{Michael Nelson}

How to Live Longer and Feel Better. By Linus Pauling. W.H. Freeman:1986. Pp.322. Hbk \$15.95, £15.95; pbk \$7.95, $£ 5.95$.

AN ELDERLY relative from America visited me recently in London. At breakfast each morning she swallowed a vast array of vitamin tablets, one "for cholesterol", one "for colds", one "for skin" and so on. "Do you feel any better for taking them?" I asked. "No", she replied, "but I think I ought to and they don't seem to do me any harm".

In How to Live Longer and Feel Better, Linus Pauling uses equally uncompelling arguments to try and convince readers of the benefits of the megavitamin treatment of life. He begins by describing "The Regimen" for better health, outlining in declamatory fashion his reasons for consuming anywhere between 10 and 3,000 times the recommended intakes of most known vitamins, with emphasis on the particular value of vitamin C. He then discusses the roles of protein, fat, carbohydrates, energy, water (and, of course, vitamin $\mathrm{C}$ ) in maintaining health, and provides some sensible if unoriginal ideas about balanced eating and avoiding fad diets. His emphasis on the protective role of vitamins, however, is at odds with current epidemiological evidence regarding the effects on health of smoking, excess weight and lack of exercise. This first section also contains a number of irritating nutritional inaccuracies (for example that starch is found in all fruit, that vegetarian diets cannot provide the correct balance of essential amino acids, that seeds and nuts are low in vitamins).

Dr Pauling regards vitamins as food, and so makes the absurd suggestion that "It is wise to supplement the vitamin supplements with a good intake of fruits and vegetables" (p.31) - this is standing nutrition on its head. Also, I am instinctively wary of advice which tells me that "swallowing not more than a half-dozen tablets a day" isn't burdensome, and find misguided the remark that a regimen adding $£ 7$ to a weekly food bill is inexpensive.

The second section, "The New Nutrition", begins with promise. A history of the discovery of vitamins is followed by an interesting chapter on vitamins and evolution. Unhappily, this degenerates into an attempt to establish optimal levels of vitamin $\mathrm{C}$ intake for human beings based solely on comparative physiology. Analo-

\section{IMAGE UNAVAILABLE FOR COPYRIGHT REASONS}

"HCTUALLY I STARTED OUT IN QUANTUM MECHANICS, BUT SOMEWHERE ALONG THE "WAY I TOOK A WRONG TURN."

gies with pigs, cats, monkeys and goats provide interesting but unconvincing evidence for the optimal human requirement, and direct evidence from experiments on healthy people is sorely lacking.

The third section on orthomolecular medicine is, frankly, tedious. There is very little here that has not already been said elsewhere. For illness after illness, from the common cold to AIDS, Dr Pauling presents repetitive and wholly one-sided arguments in favour of treatment with massive doses of vitamin C. Those few studies quoted which do not support his contentions are dismissed for having failed to provide sufficiently large and lengthy doses to be effective. This lack of balance lends an evangelical tone to his writing and casts justifiable doubt on his interpretation of others' findings. For example, Knox's data on deaths from heart disease (Lancet, 1, 1465-1466; 1973) did not, as Pauling claims, show an association with vitamin $\mathrm{C}$ "greater than that for any other factor" (p.151). The correlation between regional mortality from heart disease and diet was greatest for calcium $(r=-0.67)$, not vitamin $C$ $(-0.49)$, and in a multiple regression analysis, calcium, fat and vitamin $\mathrm{D}$ - not $\mathrm{C}$ - were the most significantly correlated variables.

This book, then, is for the lay audience which wants to be convinced that life will be happier and longer if Dr Pauling's prescription is followed. It is not for epidemiologists or nutritionists who are looking for reasoned arguments on the merits of vitamins in the prevention of disease. There is a comprehensive bibliography of interest to those who wish to look into the subject themselves and draw their own conclusions.

Michael Nelson is a Lecturer in the Department of Food and Nutritional Science, Kings College London (KQC), Campden Hill Road, London W8 $7 A H, U K$. 